\title{
Toward Earlier Diagnosis Using Combined eHealth Tools in Rheumatology: The Joint Pain Assessment Scoring Tool (JPAST) Project
}

Johannes Knitza ${ }^{1}$, MD; Rachel Knevel, ${ }^{2,3}$, MD; Karim Raza ${ }^{4,5}$, MD; Tor Bruce ${ }^{6}$, BAPSC; Ekaterina Eimer ${ }^{7}$, Dr rer nat; Isabel Gehring ${ }^{7}$, Dr rer nat; Linda Mathsson-Alm ${ }^{8}, \mathrm{PhD}$; Maryam Poorafshar ${ }^{8}, \mathrm{PhD}$; Axel J Hueber ${ }^{1}, \mathrm{MD}$; Georg $\mathrm{Schett}^{1}, \mathrm{MD}$; Martina Johannesson ${ }^{9}, \mathrm{PhD}$; Anca Catrina ${ }^{9}, \mathrm{MD}$; Lars Klareskog ${ }^{9}$, MD; JPAST Group ${ }^{9}$

${ }^{1}$ Department of Internal Medicine 3 - Rheumatology and Immunology, Friedrich-Alexander University Erlangen-Nürnberg, University Hospital Erlangen, Erlangen, Germany

${ }^{2}$ Department of Rheumatology, Leiden University Medical Center, Leiden, Netherlands

${ }^{3}$ Division of Rheumatology, Inflammation and Immunity, Brigham and Women's Hospital, Harvard Medical School, Boston, MA, United States

${ }^{4}$ Department of Rheumatology, Sandwell and West, Birmingham Hospitals NHS Trust, Birmingham, United Kingdom

${ }^{5}$ Institute of Inflammation and Ageing, University of Birmingham, Birmingham, United Kingdom

${ }^{6}$ Ocean Observations, Stockholm, Sweden

${ }^{7}$ Thermo Fisher Scientific, Freiburg, Germany

${ }^{8}$ Thermo Fisher Scientific, Uppsala, Sweden

${ }^{9}$ Division of Rheumatology, Department of Medicine, Karolinska Institutet, Karolinska University Hospital, Stockholm, Sweden

\section{Corresponding Author:}

Johannes Knitza, MD

Department of Internal Medicine 3 - Rheumatology and Immunology

Friedrich-Alexander University Erlangen-Nürnberg

University Hospital Erlangen

Ulmenweg 18

Erlangen, 91054

Germany

Phone: 4991318532093

Fax: 4991318532092

Email: johannes.knitza@uk-erlangen.de

\section{Abstract}

Outcomes of patients with inflammatory rheumatic diseases have significantly improved over the last three decades, mainly due to therapeutic innovations, more timely treatment, and a recognition of the need to monitor response to treatment and to titrate treatments accordingly. Diagnostic delay remains a major challenge for all stakeholders. The combination of electronic health (eHealth) and serologic and genetic markers holds great promise to improve the current management of patients with inflammatory rheumatic diseases by speeding up access to appropriate care. The Joint Pain Assessment Scoring Tool (JPAST) project, funded by the European Union (EU) European Institute of Innovation and Technology (EIT) Health program, is a unique European project aiming to enable and accelerate personalized precision medicine for early treatment in rheumatology, ultimately also enabling prevention. The aim of the project is to facilitate these goals while at the same time, reducing cost for society and patients.

(JMIR Mhealth Uhealth 2020;8(5):e17507) doi: 10.2196/17507

\section{KEYWORDS}

rheumatology; eHealth; mHealth; symptom-checkers; apps 


\section{Background}

The path to a correct diagnosis and efficacious treatment is often long and frustrating for patients with inflammatory rheumatic and musculoskeletal diseases (RMDs). This is a major problem as both short and long treatment efficacy depends on early and correct diagnosis. Early diagnosis for rheumatoid arthritis (RA), systemic lupus erythematosus (SLE), myositis, primary Sjögren syndrome (SS), and systemic sclerosis (SSc) is critical for improved disease outcomes and the selection of a therapy strategy. For example, in the context of RA, the first 3 months of symptoms have been identified as a therapeutic window during which immunologic mechanisms can still be altered $[1,2]$. Therefore, the European League Against Rheumatism (EULAR) recommends that any patient presenting with morning stiffness or joint pain or swollen joints sees a rheumatologist no later than 6 weeks after symptom onset [3]. Interestingly, the advice to see a rheumatologist for persistent joint pain poses a particular challenge, as joint pain is very common in the population [4]. However, certain variants of joint pain together with the presence of rheumatoid factor $(\mathrm{RF})$ or anticitrullinated protein antibody (ACPA) indicate a high risk for the development of RA. When identified, such individuals can be given lifestyle advice to reduce the risk of disease development and an opportunity to participate in clinical trials aimed at prevention of RA. Notably, novel ways of identifying patients at risk on a large scale will be needed if ongoing preventive trials are successful and will lead to a change in clinical practice.

\section{Diagnostic Delay in Today's Clinical Practice}

Diagnostic delay [5] is one of the biggest current challenges in rheumatology. Rheumatic symptoms such as joint pain are common and hard to evaluate for patients and health care providers [6-8]. Patients often wait too long as they believe that the symptoms will resolve spontaneously [9] or with self-care methods [10]. General practitioners (GP) find it hard to identify RMD symptoms indicative of emerging RA or other inflammatory RMD at early stages in the disease course [11]. The resulting delay may exacerbate existing health disparities $[10,11]$. Furthermore, rheumatologists remain scarce worldwide [12], and this represents one of the main reasons for the delay in diagnosis. Notably, the early and correct identification of patients with emerging rheumatic diseases based solely on clinical evaluation is very challenging even for experienced rheumatologists [13].

\section{Improving Health Care Efficiency}

In addition to the challenge of reducing diagnostic delay, there is an increasing need to optimize health care efficiency. Musculoskeletal complaints account for $21.3 \%$ of the years lived with disabilities, with neck pain and low back pain accounting for almost $70 \%$ [14]. Up to $60 \%$ of patients presenting to rheumatologists in many countries turn out to have no inflammatory rheumatic diseases [15] (Figure 1). Given that the prevalence of musculoskeletal complaints increases with age, the increasing age of most populations will lead to a systemic overload of health care systems. The solution to such situations is to classically triage patients to allow prioritization based on the level of urgency and availability of effective treatment. There are different strategies $[16,17]$ to accelerate access to rheumatologists, although low-barrier electronic health (eHealth)-based approaches remain rare. In emergency departments, heterogeneous triage decisions led to the creation and use of triage standards such as the widely used Manchester-Triage-System [18]. In rheumatology, no triage system has yet been widely accepted [16] and various local systems are being used [19]. The lack of transparent and objective standards for triage [20] represents a major hurdle for early diagnosis in patients where early treatment could make a large difference. 
Figure 1. Diagnostic delay and inefficient health care service. GP: general practitioner. *Powley et al [21]. **Stack et al [10]. ***Feuchtenberger et al [15].

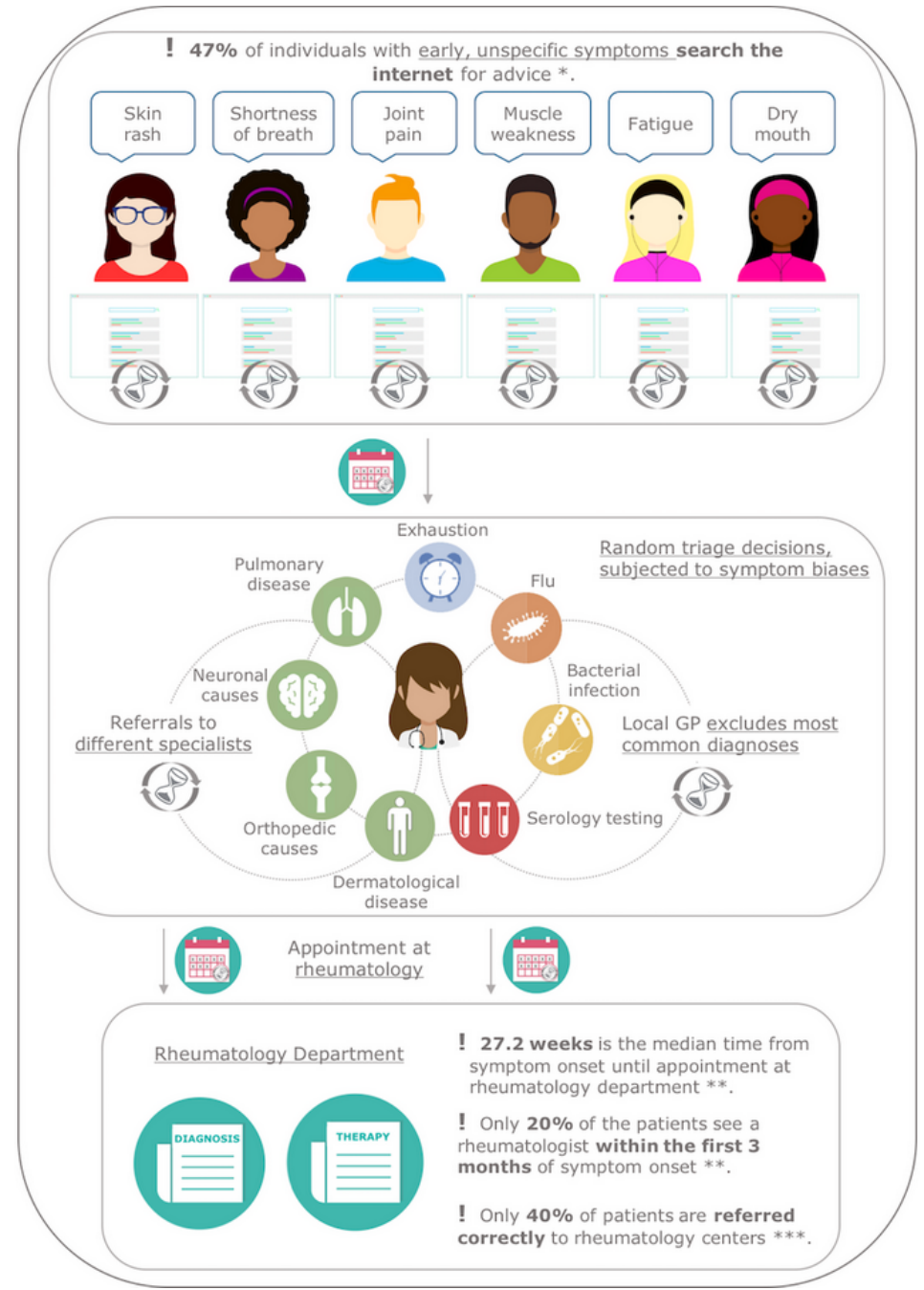

\section{The Value of Current Symptom Checkers in Rheumatology}

The internet is an important source of information for both health care professionals and members of the public. Patients often check their symptoms online prior to seeing a rheumatologist [21]. Symptom checkers represent a professional alternative to search engines. They represent a patient-facing version of a diagnostic decision support system (DDSS). These systems have existed for a long time, yet are rarely used in clinical practice. Based on the patient's reported symptoms, these systems generate a list of probable diagnoses and offer advice on further steps. These tools can potentially reduce the number of delayed and incorrect diagnoses [22]. Two systematic reviews showed that the diagnostic accuracy of physicians could be improved by using DDSS [23,24]. A retrospective evaluation that applied a DDSS on medical records of patients with rare diseases showed that the median advantage of correct disease suggestions compared to the time of clinical diagnosis was 3 months [25]. The use of symptom checkers in rheumatology has been explored only on a minor level. Powley et al [21] recently evaluated two freely available symptom checkers which included a broad variety of different diseases, and were thus not rheumatology-specific. The study showed that the help-seeking advice and diagnoses given by the symptom checkers tested was frequently inaccurate for rheumatic diseases, correctly identifying inflammatory arthritis in only 4 of 21 (19\%) patients. The NHS (National Health Service) symptom checker inappropriately suggested that nearly half of patients should seek advice from emergency services. This phenomenon is well known for symptom checkers, as most systems perform in a relatively risk-adverse manner [26]. Symptom checkers promise to support patients, GPs, and rheumatologists in making the correct diagnosis in a timely manner using minimal resources with little burden; however, more evidence is needed to prove their clinical and economic benefit.

\section{Incorporation of Serological and Genetic Data}

Subjectivity is an inherent weakness of symptom checkers. The possibility to combine the outcome from symptom checkers with serological and genetic biomarkers is likely to drastically improve early differentiation between patients with and without autoimmune inflammatory RMDs. This would shorten the time it takes for patients to get access to specialist care (Figure 2). Several serological biomarkers are included in the American College of Rheumatology (ACR)/EULAR classification criteria 
for RMDs (eg, ACPA and RF in RA [27], anti-dsDNA and anti-Sm in SLE [28], Scl70, anti-CENP and anti-RNA polymerase III in SSc [29], anti-Jo-1 in myositis [30] and anti-SSA/Ro in SS [31]). Such biomarkers can be present years before the onset of symptoms [32]. Early diagnostic biomarker panels and biomarkers with predictive utility are needed to guide clinical decision-making in rheumatology. The contribution of genetic variants to the individual risk of patients developing
RMDs was highlighted in several twin studies [33,34]. Recently, genome-wide association studies (GWAS) have highlighted specific genes (eg, HLA, STAT4, TNF, PTPN22) for their contribution. Combinations of different genetic risk factors could contribute to the overall differentiation of patients at risk of developing inflammatory RMDs compared with other noninflammatory, nonautoimmune diseases.

Figure 2. Shorter patient journey and more efficiency in health care with JPAST (Joint Pain Assessment Scoring Tool). AI: artificial intelligence; GP: general practitioner.

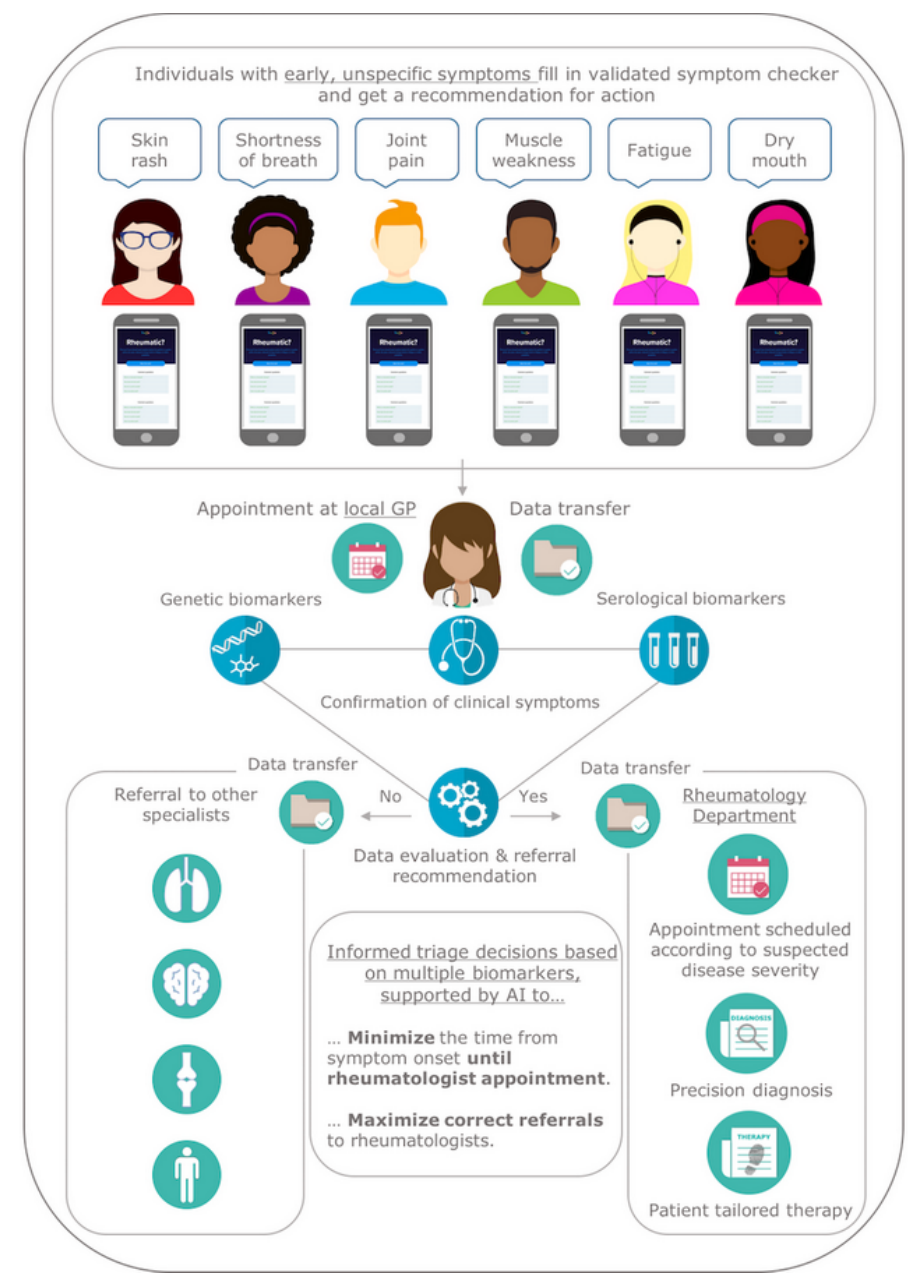

Next-generation technologies have emerged, allowing fast and easy analyses of multiple serology and genetic markers. The early identification of high-risk patients allows them and their physicians to make effective lifestyle and medication changes to reduce the risk of future disease activity. The combination and interrogation of clinical, serological, and genetic data could allow the precise and early separation and description of phenotypes; currently available machine learning approaches offer particular promise in relation to this [35]. The digital documentation of symptoms and complete electronic patient records enable the identification of current treatment bottlenecks, although implementation into the digital infrastructure at the GP level and in different hospital information systems will be a challenge. Using these data, process enhancement will allow the optimization of the current health care situation [36].

\section{Joint Pain Assessment Scoring Tool}

The objective of the Joint Pain Assessment Scoring Tool (JPAST) project, a digital diagnostic program supported by EU/EIT, is to improve the early differentiation between patients with and without autoimmune inflammatory RMDs and in addition to identify individuals at very high risk for these diseases (Figure 2). To our knowledge JPAST is the first project combining patient symptoms, genetics, and serology biomarkers for these purposes. The intention is that JPAST will eventually be tested at leading university hospitals in Europe and subsequently be implemented elsewhere to accelerate access to rheumatology services and appropriate therapy.

The current version of the JPAST eHealth tool, "Rheumatic?" (Figure 3 and Multimedia Appendix 1), is available in English, Swedish, Dutch, and German. "Rheumatic?" is a website with responsive web design, making it adaptable for smartphone and 
tablet use. The interface consists of single-choice buttons, multiple-choice buttons, image area questions, single-choice sliders, and pain sliders (Multimedia Appendix 1). The questions are individualized, as the next question depends on the previous answer. The scoring system was developed to be flexible and adapt to any needs that came up during the project. To achieve this, we created a system of reusable, recursive point buckets. Every point bucket has two threshold values, and a list of assigned points for any number of question options. To evaluate the point bucket, all the selected question options and their total points are calculated. The points can be positive or negative.
The sum is compared to the threshold values to see if either threshold should be considered active. The recursive element comes into play when a point bucket assigns points not just directly to one particular option, but also to a threshold in another point bucket. For example, this allows us to create point buckets that are activated on individual symptoms, and then assign different scores to these symptoms for different diseases. This decouples the way points are assigned from the way the questions are asked, and allows more sophisticated scoring logic and more convenient reuse of points. Patients and physicians worked together to develop these tools.

Figure 3. Screenshots of "Rheumatic?" the JPAST (Joint Pain Assessment Scoring Tool) symptom checker.

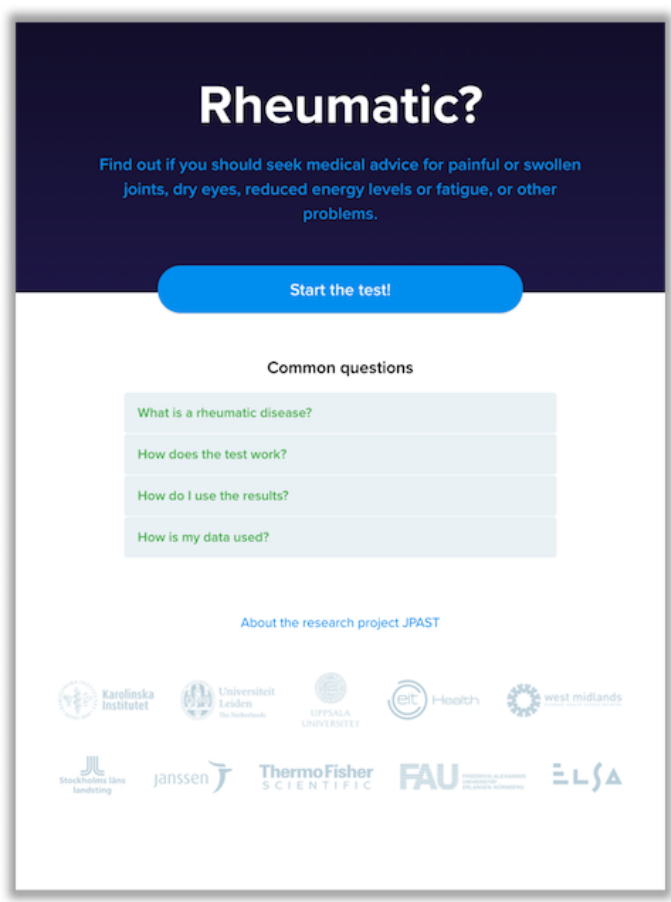

Furthermore, specific serology-based multiplex assays and next generation sequencing panels are also being developed and will be integrated with the "Rheumatic?" eHealth tool. These assays are currently being validated using blood samples from the 5 key RMDs: rheumatoid arthritis, idiopathic inflammatory myopathies, systemic lupus erythematosus, Sjögren syndrome, and systemic sclerosis. An algorithm including genetic markers, serological markers, and clinical data will provide information to the patient and the care provider. This will help in early diagnosis of an existing disease as well as in estimating the risk for an emerging rheumatic disease in individuals with symptoms such as joint pain but without current signs of inflammation. As proposed by Weyrich et al [37] this triage system is user-friendly, dynamic, and incorporates the potential of eHealth [38]. A recent review [38] identified a lack of mHealth and
eHealth tools in the field of rheumatology, underlining the innovative and stand-alone character of the JPAST project. In the first step, the diagnostic accuracy of JPAST and its usability will be analyzed in patients newly presenting to secondary care-based rheumatology clinics to test its usefulness. JPAST performance can then be compared to currently used local screening methods [17], which will allow further algorithm improvement. Once an acceptable level of performance is achieved, a prospective primary care-based long-term study should compare the clinical and economic impact of using this system versus current local care [39]. We believe JPAST will provide an accelerated pathway and improved personalized diagnosis of autoimmune inflammatory RMDs by combining innovative products and services and including all main stakeholders.

\section{Acknowledgments}

The authors thank all partners and collaborators for their support of this project. JPAST is a public-private partnership program for the digitalization of health care, supported by EIT Health. This project has received funding from EIT Health. EIT Health is supported by the European Institute of Innovation and Technology (EIT), a body of the European Union that receives support from the European Union's Horizon 2020 Research and Innovation program. Thermo Fisher Scientific is the participating diagnostic company developing the serology and genetics tools. Scientists/clinicians from the four contributing and coauthoring centers have developed the eHealth tool "Rheumatic?" with help from the strategic design agency Ocean. 


\section{Authors' Contributions}

All authors wrote, reviewed, and approved the final manuscript. Further members of the JPAST Group are as follows: Monika Hansson (Division of Rheumatology, Department of Medicine, Karolinska Institutet, Karolinska University Hospital, Stockholm, Sweden), Sascha Swiniarski (Thermo Fisher Scientific, Freiburg, Germany), Leonid Padyukov (Division of Rheumatology, Department of Medicine, Karolinska Institutet, Karolinska University Hospital, Stockholm, Sweden), Caroline Grönwall (Division of Rheumatology, Department of Medicine, Karolinska Institutet, Karolinska University Hospital, Stockholm, Sweden), Tom Huizinga (Department of Rheumatology, Leiden University Medical Center, Leiden, The Netherlands), Andrew Filer (Institute of Inflammation and Ageing, University of Birmingham, Birmingham, UK), Sofia Svanteson (Ocean Observations, Stockholm, Sweden), Alexandra Lindfors (Ocean Observations, Stockholm, Sweden), and Aase Hensvold (Division of Rheumatology, Department of Medicine, Karolinska Institutet, Karolinska University Hospital, Stockholm, Sweden).

\section{Conflicts of Interest}

LK is a board member of the Riskminder Foundation, which has ownership in the eHealth company Elsa, which aims to continue the development of certain aspects of the JPAST tools. EE, IG, LMA, and MP work for Thermo Fisher Scientific. TB works for Ocean Observations. The other authors declare no conflicts of interest.

\section{Multimedia Appendix 1}

Screencast of "Rheumatic?" the JPAST (Joint Pain Assessment Scoring Tool) symptom checker. [MOV File, 22792 KB-Multimedia Appendix 1]

\section{References}

1. Quinn MA, Emery P. Window of opportunity in early rheumatoid arthritis: possibility of altering the disease process with early intervention. Clin Exp Rheumatol 2003;21(5 Suppl 31):S154-S157. [Medline: 14969068]

2. Smolen JS, Aletaha D, McInnes IB. Rheumatoid arthritis. Lancet 2016 Oct 22;388(10055):2023-2038. [doi: 10.1016/S0140-6736(16)30173-8] [Medline: 27156434]

3. Combe B, Landewe R, Daien CI, Hua C, Aletaha D, Álvaro-Gracia JM, et al. 2016 update of the EULAR recommendations for the management of early arthritis. Ann Rheum Dis 2016 Dec 15;76(6):948-959. [doi: 10.1136/annrheumdis-2016-210602]

4. Hider SL, Muller S, Helliwell T, Prior JA, Scott I, Lawton SA, et al. Symptoms associated with inflammatory arthritis are common in the primary care population: results from the joint symptoms survey. Rheumatology (Oxford) 2019 Nov 01;58(11):2009-2014. [doi: 10.1093/rheumatology/kez184] [Medline: 31079150]

5. Raza K, Stack R, Kumar K, Filer A, Detert J, Bastian H, et al. Delays in assessment of patients with rheumatoid arthritis: variations across Europe. Ann Rheum Dis 2011 Aug 07;70(10):1822-1825. [doi: 10.1136/ard.2011.151902]

6. Simons G, Belcher J, Morton C, Kumar K, Falahee M, Mallen CD, et al. Symptom Recognition and Perceived Urgency of Help-Seeking for Rheumatoid Arthritis and Other Diseases in the General Public: A Mixed Method Approach. Arthritis Care \& Research 2017 Apr 10;69(5):633-641. [doi: 10.1002/acr.22979]

7. Simons G, Lumley S, Falahee M, Kumar K, Mallen CD, Stack RJ, et al. The pathway to consultation for rheumatoid arthritis: exploring anticipated actions between the onset of symptoms and face-to-face encounter with a healthcare professional. BMC Musculoskelet Disord 2017 Jun 14;18(1). [doi: 10.1186/s12891-017-1619-9]

8. Kumar K, Daley E, Carruthers DM, Situnayake D, Gordon C, Grindulis K, et al. Delay in presentation to primary care physicians is the main reason why patients with rheumatoid arthritis are seen late by rheumatologists. Rheumatology 2007 Jun 27;46(9):1438-1440. [doi: 10.1093/rheumatology/kem130]

9. Raciborski F, Kłak A, Kwiatkowska B, Batko B, Sochocka-Bykowska M, Zoń-Giebel A, working team. Diagnostic delays in rheumatic diseases with associated arthritis. Reumatologia 2017;55(4):169-176 [FREE Full text] [doi:

10.5114/reum.2017.69777] [Medline: 29056771]

10. Stack RJ, Nightingale P, Jinks C, Shaw K, Herron-Marx S, Horne R, et al. Delays between the onset of symptoms and first rheumatology consultation in patients with rheumatoid arthritis in the UK: an observational study. BMJ Open 2019 Mar 04;9(3):e024361. [doi: 10.1136/bmjopen-2018-024361]

11. van der Linden MPM, le Cessie S, Raza K, van der Woude D, Knevel R, Huizinga TWJ, et al. Long-term impact of delay in assessment of patients with early arthritis. Arthritis \& Rheumatism 2010 Nov 30;62(12):3537-3546. [doi: 10.1002/art.27692]

12. Zink A, Schneider M. Versorgungsplanung in der Rheumatologie: Eckpunkte aus dem 2016 aktualisierten Memorandum der Deutschen Gesellschaft für Rheumatologie zur Versorgungsqualität. Akt Rheumatol 2018 Mar 21;43(05):390-394. [doi: 10.1055/a-0573-8722]

13. Ehrenstein B, Pongratz G, Fleck M, Hartung W. The ability of rheumatologists blinded to prior workup to diagnose rheumatoid arthritis only by clinical assessment: a cross-sectional study. Rheumatology (Oxford) 2018 Sep 01;57(9):1592-1601. [doi: 10.1093/rheumatology/key127] [Medline: 29850885]

14. March L, Smith EU, Hoy DG, Cross MJ, Sanchez-Riera L, Blyth F, et al. Burden of disability due to musculoskeletal (MSK) disorders. Best Practice \& Research Clinical Rheumatology 2014 Jun;28(3):353-366. [doi: 10.1016/j.berh.2014.08.002] 
15. Feuchtenberger M, Nigg AP, Kraus MR, Schäfer A. Rate of Proven Rheumatic Diseases in a Large Collective of Referrals to an Outpatient Rheumatology Clinic under Routine Conditions. Clin Med Insights Arthritis Musculoskelet Disord 2016 Oct 02;9:181-187. [doi: 10.4137/cmamd.s40361]

16. Villeneuve E, Nam JL, Bell MJ, Deighton CM, Felson DT, Hazes JM, et al. A systematic literature review of strategies promoting early referral and reducing delays in the diagnosis and management of inflammatory arthritis. Ann Rheum Dis 2012 Apr 24;72(1):13-22. [doi: 10.1136/annrheumdis-2011-201063]

17. Benesova K, Lorenz H, Lion V, Voigt A, Krause A, Sander O, et al. Früh- und Screeningsprechstunden: Ein notwendiger Weg zur besseren Frühversorgung in der internistischen Rheumatologie? Z Rheumatol 2019 Aug 29;78(8):722-742. [doi: 10.1007/s00393-019-0683-y]

18. Krey J. "To triage or not to triage" ... (frei nach Shakespeare). Med Klin Intensivmed Notfmed 2016 Jul 18;111(6):565-566. [doi: $10.1007 / \mathrm{s} 00063-016-0200-\mathrm{x}$ ]

19. Thompson AE, Haig SL, LeRiche NG, Rohekar G, Rohekar S, Pope JE. Comprehensive Arthritis Referral Study — Phase 2: Analysis of the Comprehensive Arthritis Referral Tool. J Rheumatol 2014 Sep 01;41(10):1980-1989. [doi: 10.3899/jrheum.140167]

20. Gerdtz MF, Chu M, Collins M, Considine J, Crellin D, Sands N, et al. Factors influencing consistency of triage using the Australasian Triage Scale: implications for guideline development. Emerg Med Australas 2009 Aug;21(4):277-285. [doi: 10.1111/j.1742-6723.2009.01197.x] [Medline: 19682012]

21. Powley L, McIlroy G, Simons G, Raza K. Are online symptoms checkers useful for patients with inflammatory arthritis? BMC Musculoskelet Disord 2016 Dec 24;17(1):362 [FREE Full text] [doi: 10.1186/s12891-016-1189-2] [Medline: 27553253]

22. El-Kareh R, Hasan O, Schiff GD. Use of health information technology to reduce diagnostic errors. BMJ Qual Saf 2013 Oct;22 Suppl 2:ii40-ii51 [FREE Full text] [doi: 10.1136/bmjqs-2013-001884] [Medline: 23852973]

23. Garg AX, Adhikari NKJ, McDonald H, Rosas-Arellano MP, Devereaux PJ, Beyene J, et al. Effects of computerized clinical decision support systems on practitioner performance and patient outcomes: a systematic review. JAMA 2005 Mar 9;293(10):1223-1238. [doi: 10.1001/jama.293.10.1223] [Medline: 15755945]

24. Riches N, Panagioti M, Alam R, Cheraghi-Sohi S, Campbell S, Esmail A, et al. The Effectiveness of Electronic Differential Diagnoses (DDX) Generators: A Systematic Review and Meta-Analysis. PLoS One 2016;11(3):e0148991 [FREE Full text] [doi: 10.1371/journal.pone.0148991] [Medline: 26954234]

25. Ronicke S, Hirsch MC, Türk E, Larionov K, Tientcheu D, Wagner AD. Can a decision support system accelerate rare disease diagnosis? Evaluating the potential impact of Ada DX in a retrospective study. Orphanet J Rare Dis 2019 Dec 21;14(1):69 [FREE Full text] [doi: 10.1186/s13023-019-1040-6] [Medline: $\underline{\text { 30898118] }}$

26. Semigran HL, Linder JA, Gidengil C, Mehrotra A. Evaluation of symptom checkers for self diagnosis and triage: audit study. BMJ 2015;351:h3480 [FREE Full text] [Medline: 26157077]

27. Aletaha D, Neogi T, Silman AJ, Funovits J, Felson DT, Bingham CO, et al. 2010 Rheumatoid arthritis classification criteria: an American College of Rheumatology/European League Against Rheumatism collaborative initiative. Arthritis Rheum 2010 Sep;62(9):2569-2581 [FREE Full text] [doi: 10.1002/art.27584] [Medline: 20872595]

28. Aringer M, Costenbader KH, Dörner T, Johnson SR. Limited role of specificity of ANA for SLE classification. Response to: 'European League against Rheumatism/American College of Rheumatology classification criteria for systemic lupus erythematosus: the laboratory immunologist's point of view' by Infantino. Ann Rheum Dis 2019 Dec 12;78(9):1151. [doi: 10.1136/annrheumdis-2019-216700]

29. van den Hoogen F, Khanna D, Fransen J, Johnson S, Baron M, Tyndall A, et al. 2013 classification criteria for systemic sclerosis: an American college of rheumatology/European league against rheumatism collaborative initiative. Ann Rheum Dis 2013 Nov;72(11):1747-1755. [doi: 10.1136/annrheumdis-2013-204424] [Medline: 24092682]

30. Lundberg IE, Tjärnlund A, Bottai M, Werth VP, Pilkington C, Visser M, International Myositis Classification Criteria Project consortium, The Euromyositis register, The Juvenile Dermatomyositis Cohort Biomarker Study and Repository (JDRG) (UKIreland). 2017 European League Against Rheumatism/American College of Rheumatology classification criteria for adult and juvenile idiopathic inflammatory myopathies and their major subgroups. Ann Rheum Dis 2017 Dec;76(12):1955-1964 [FREE Full text] [doi: 10.1136/annrheumdis-2017-211468] [Medline: 29079590]

31. Shiboski CH, Shiboski SC, Seror R, Criswell LA, Labetoulle M, Lietman TM, et al. 2016 American College of Rheumatology/European League Against Rheumatism classification criteria for primary Sjögren's syndrome. Ann Rheum Dis 2016 Oct 26;76(1):9-16. [doi: 10.1136/annrheumdis-2016-210571]

32. Rantapää-Dahlqvist S, de Jong BAW, Berglin E, Hallmans G, Wadell G, Stenlund H, et al. Antibodies against cyclic citrullinated peptide and IgA rheumatoid factor predict the development of rheumatoid arthritis. Arthritis \& Rheumatism 2003 Oct 07;48(10):2741-2749. [doi: 10.1002/art.11223]

33. Svendsen AJ, Kyvik KO, Houen G, Junker P, Christensen K, Christiansen L, et al. On the Origin of Rheumatoid Arthritis: The Impact of Environment and Genes-A Population Based Twin Study. PLoS ONE 2013 Feb 28;8(2):e57304. [doi: 10.1371/journal.pone.0057304]

34. Eroglu GE, Kohler PF. Familial systemic lupus erythematosus: the role of genetic and environmental factors. Ann Rheum Dis 2002 Jan;61(1):29-31 [FREE Full text] [doi: 10.1136/ard.61.1.29] [Medline: 11779754] 
35. Drouin A, Letarte G, Raymond F, Marchand M, Corbeil J, Laviolette F. Interpretable genotype-to-phenotype classifiers with performance guarantees. Sci Rep 2019 Mar 11;9(1). [doi: 10.1038/s41598-019-40561-2]

36. Thrall JH. Data Mining, Knowledge Creation, and Work Process Enhancement in the Second Generation of Radiology's Digital Age. Journal of the American College of Radiology 2013 Mar;10(3):161-162. [doi: 10.1016/j.jacr.2012.08.007]

37. Weyrich P, Christ M, Celebi N, Riessen R. Triagesysteme in der Notaufnahme. Med Klin Intensivmed Notfmed 2012 Feb 1;107(1):67-79. [doi: 10.1007/s00063-011-0075-9]

38. Knitza J, Tascilar K, Messner E, Meyer M, Vossen D, Pulla A, et al. German Mobile Apps in Rheumatology: Review and Analysis Using the Mobile Application Rating Scale (MARS). JMIR mHealth uHealth 2019 Aug 05;7(8):e14991 [FREE Full text] [doi: 10.2196/14991] [Medline: 31381501]

39. Schwarting A, Dreher M, Assmann G, Witte T, Hoeper K, Schmidt RE. Erfahrungen und Ergebnisse aus Rheuma-VOR. Z Rheumatol 2019 Aug 29;78(8):743-752. [doi: 10.1007/s00393-019-00694-1]

\author{
Abbreviations \\ ACPA: anticitrullinated protein antibody \\ ACR: American College of Rheumatology \\ DDSS: diagnostic decision support system \\ eHealth: electronic health \\ EIT: European Institute of Innovation and Technology \\ EU: European Union \\ EULAR: European League Against Rheumatism \\ GP: general practitioner \\ GWAS: genome-wide association studies \\ JPAST: Joint Pain Assessment Scoring Tool \\ NHS: National Health Service \\ RA: rheumatoid arthritis \\ RF: rheumatoid factor \\ RMD: rheumatic and musculoskeletal diseases \\ SLE: systemic lupus erythematosus \\ SS: Sjögren syndrome \\ SSc: systemic sclerosis
}

\author{
Edited by G Eysenbach; submitted 17.12.19; peer-reviewed by M Wong, B Eapen, F Dittrich; comments to author 31.01.20; revised \\ version received 10.02.20; accepted 22.03.20; published 15.05.20 \\ Please cite as: \\ Knitza J, Knevel R, Raza K, Bruce T, Eimer E, Gehring I, Mathsson-Alm L, Poorafshar M, Hueber AJ, Schett G, Johannesson M, \\ Catrina A, Klareskog L, JPAST Group \\ Toward Earlier Diagnosis Using Combined eHealth Tools in Rheumatology: The Joint Pain Assessment Scoring Tool (JPAST) Project \\ JMIR Mhealth Uhealth 2020;8(5):e17507 \\ URL: https://mhealth.jmir.org/2020/5/e17507 \\ doi: 10.2196/17507 \\ PMID: 32348258
}

CJohannes Knitza, Rachel Knevel, Karim Raza, Tor Bruce, Ekaterina Eimer, Isabel Gehring, Linda Mathsson-Alm, Maryam Poorafshar, Axel J Hueber, Georg Schett, Martina Johannesson, Anca Catrina, Lars Klareskog, JPAST Group. Originally published in JMIR mHealth and uHealth (http://mhealth.jmir.org), 15.05.2020. This is an open-access article distributed under the terms of the Creative Commons Attribution License (https://creativecommons.org/licenses/by/4.0/), which permits unrestricted use, distribution, and reproduction in any medium, provided the original work, first published in JMIR mHealth and uHealth, is properly cited. The complete bibliographic information, a link to the original publication on http://mhealth.jmir.org/, as well as this copyright and license information must be included. 